\title{
MOdelling, Simulation AND OPTIMIZATION OF A CHEST Freezer MANUfaCtUring ArChitectUre
}

\author{
Florina Chiscop, Ioana Catalina Enache, Cicerone Laurentiu Popa, \\ Tiberiu Gabriel Dobrescu \& Costel Emil Cotet
}
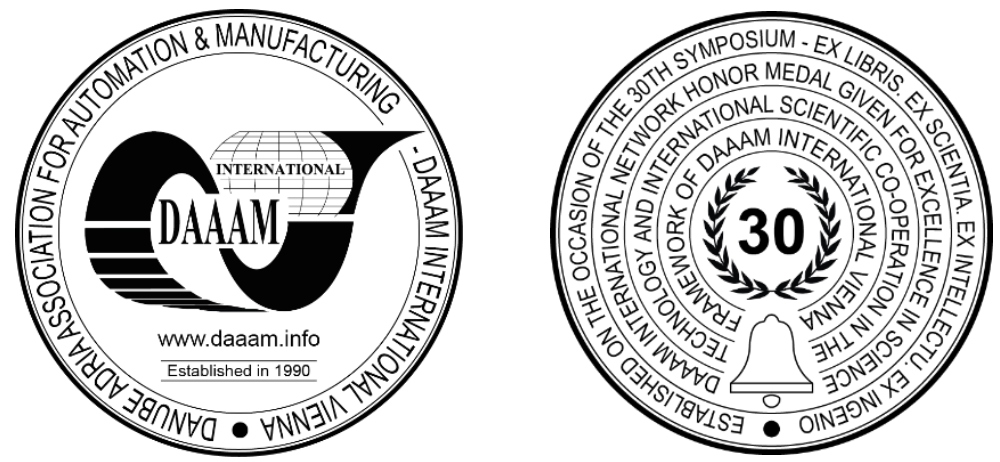

This Publication has to be referred as: Chiscop, F[lorina]; Enache, I[oana] -[ Catalina]; Popa, C[icerone] L[aurentiu]; Dobrescu, T[iberiu] \& Cotet, C[ostel] E[mil] (2019). Modelling, Simulation and Optimization of a Chest Freezer Manufacturing Architecture, Proceedings of the 30th DAAAM International Symposium, pp.0197-0206, B. Katalinic (Ed.), Published by DAAAM International, ISBN 978-3-902734-22-8, ISSN 1726-9679, Vienna, Austria DOI: $10.2507 / 30$ th.daaam.proceedings.026

\begin{abstract}
All manufacturing and assembly systems are dealing with different difficulties caused by flow concentrators. In this paper we use an example based on a chest freezer assembly architecture consisting in several sectors to create and simulate a model representing the studied architecture using WITNESS Horizon simulation software. The main goal is to locate material flow bottlenecks. Once they are identified the slow down and / or block of the flow can be improved for obtaining an optimized architecture and to increase the productivity. The optimisation process was both functional and technological. All manufacturing processes were reorganised, which lead to reduced manufacturing times in all studied areas.
\end{abstract}

Keywords: Simulation; optimisation; Witness Horizon; production line

\section{Introduction}

The refrigerator and freezer manufacturing industry has grown over the last five years, only in U.S. the industry has grown by $5.0 \%$ due to explosive growth in housing starts, stable household debt levels and growing consumer confidence. As more consumer move into new homes, demand for new appliances, such as refrigerators and freezers, increases [1], [2].

In many cases, modern refrigerators also include additional facilities such as automatic ice makers, crushers, and dispensers, chilled water and/or juice dispensers, quick-freezing, and quick-thawing capabilities [3], [4]. The design of domestic refrigerators should consider the overall appearance of the appliance: size, shape, colour and provide specialpurpose storage compartments. These appliances should be also silent and energy efficient [5].

Considering the fact that the technological innovation accelerates the replacement of equipment which generates an increase of waste electrical and electronic equipment, the manufactures should design the products in order to make easy the disassembly processes and the recycling of components. [6].

On the market are available different types of refrigerators and freezers: single-door refrigerators, upright freezers, chest freezers etc. in this paper attention focuses on a chest freezer assembly architecture divided in five production areas. 
The methodology consists in creating and simulating a model representing the studied architecture using WITNESS Horizon simulation software. Next, in order to improve the production process and determine the low productivity causes we must perform a simulation and diagnose the layout. The main goal is to observe all production sectors thus to identify the potential bottlenecks that are directly responsible for the flow to slow down or even block it. Based on the results obtained we can start an optimisation process meant to increase productivity rates [7].

Using the diagnosis reports, the flow concentrators could be identified. There are two kinds of solutions for eliminating these concentrators by modifying the manufacturing architecture. Functional remodelling potentiates the manufacturing architecture performance by modifying the structural elements layout or functional parameters but is not introducing or eliminating structural elements. Technological remodelling allows manufacturing architecture changes also when structural elements should be added or removed [7].

After functional or technological remodelling, another material flow simulation is performed for quantifying the increasing performance of the optimized manufacturing architecture. A diffused manufacturing/assembly system can be defined as architectures with more than two work points connected by transport \& transfer systems and using deposits at local or system level [7].

Using a flow simulator one can perform two kinds of simulations: finite simulations and nonterminating simulations, with specific algorithms for each category [8].

\section{Case study overview}

As a case study we chose a manufacturing architecture for assembling chest freezers [9]. The assembly line is divided into twelve areas. The product starts as an empty cabinet and after consecutive assembly operations in which it is completely equipped and ready to leave the site. There are 36 human operators organized into 12 distinct assembly sectors. The sectors are succeeding one another, in a continuous flow, in a manner where a sector's output represents the next sector's input. Based on the observations made by specialised personal and confirmed by our thorough overall system analyses the significant flow blockages appear in the first three areas of the assembly line.

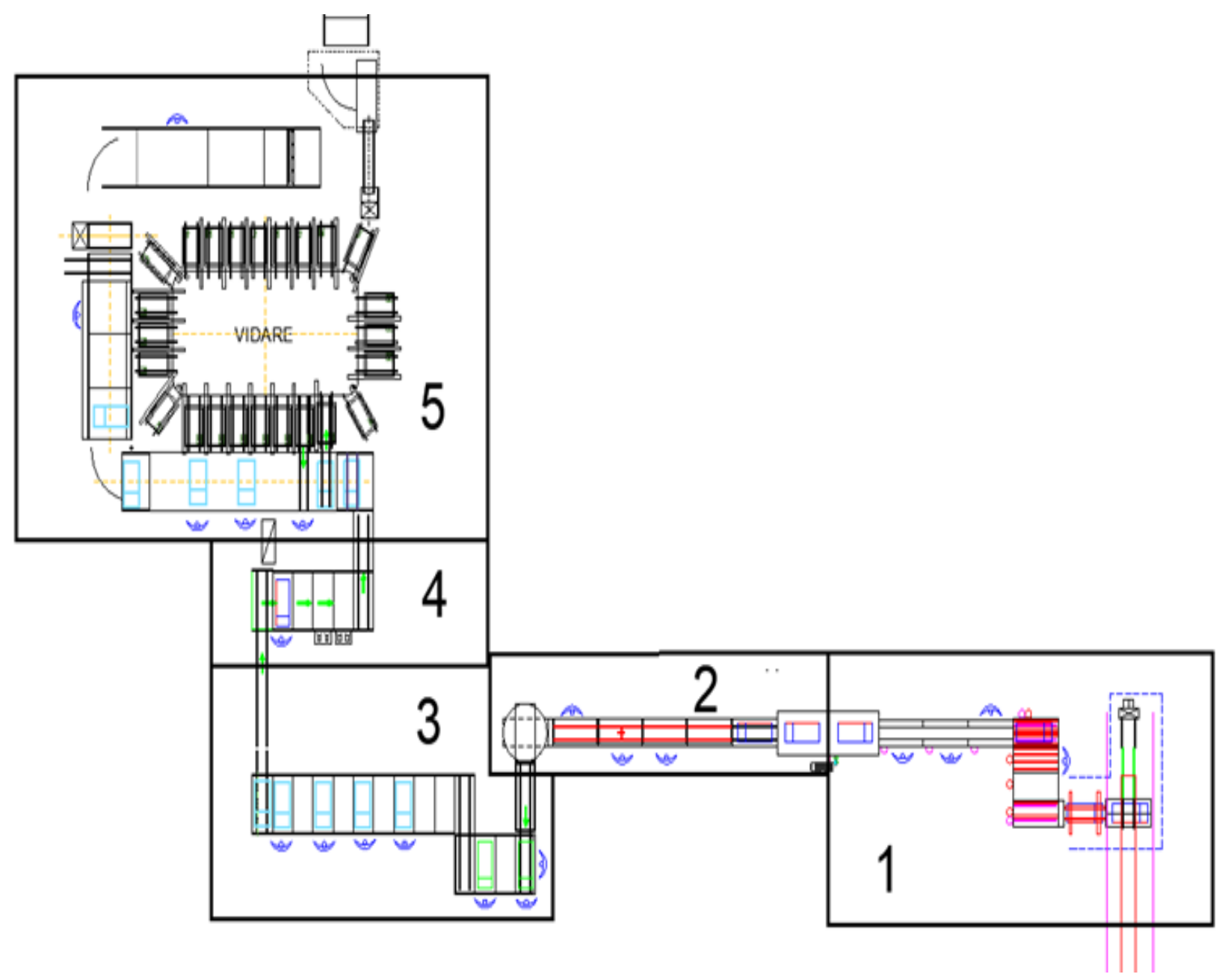

Fig. 1. First layout sectors 1 to 5 of preliminary manufacturing architecture 


\section{Rules for generating WITNESS Horizon models}

We focused our case study on the first three areas, given in Fig. 1. Given the material flow path it is very important to identify and remove flow concentrators from these sectors in order to prevent further material flow blockages on the assembly line.

As a first step in the optimisation algorithm we reproduce and simulate three models corresponding to the first three assembly areas from the manufacturing architecture using WITNESS Horizon simulation software.

The models contain elements, such as: human operators for the assembly operations, conveyor belts for transporting individual parts from one workstation to the next one and the assembled part. All structural elements were defined, displayed and parametrized according to the given layout.

\begin{tabular}{|c|c|c|}
\hline Areas & Auxiliary times [s] & Manufacturing times [s] \\
\hline Area 1 & 70 & 210 \\
\hline Area 2 & 21 & 143 \\
\hline Area 3 & 16 & 327 \\
\hline
\end{tabular}

Table 1. Manufacturing times vs. auxiliary times

To simulate the real system exploitation behaviour, we used manufacturing and auxiliary times given by the manufacturer. All times values are set in seconds and can be seen in Table 1. Manufacturing times are the ones that define the productivity rates opposed to auxiliary times that add non-value to the products.

Because we are dealing with a finite simulation, we must establish the simulated time interval before being able to run the actual material flow simulation. The company works 24 hours per day, thus we run the simulation for 28800 seconds, a work shift of 8 hours..

In order to keep track of the productivity we must define one more element ("count") in the model that will help us in counting the cabinets finished for each area during a work shift ( 8 hours). After the modelling part is completed the simulation process can be done generating activity reports for each structural element. This step is of highly importance in diagnosing the production layout.

This diagnose will help us to propose optimisation solutions after identifying flow concentrators.

\section{Preliminary manufacturing architecture}

Starting with the layout of the first sector in the preliminary manufacturing architecture we develop a model using WITNESS Horizon simulation software. The structural elements present in the first model are: human operators (named OP1 - OP4); transport systems (named C1 - C5); assembly (named cabinet).

The roles of the operators are as follows: OP1 - assembles the thermostat; OP2 - fixes the left housing compressor, mounts the left rear cabinet base and prints the label for the cabinet. Operator OP3 - fixes the right housing compressor, mounts the right rear cabinet base and fixes housing for heat coil; OP4 - mounts heat coil.

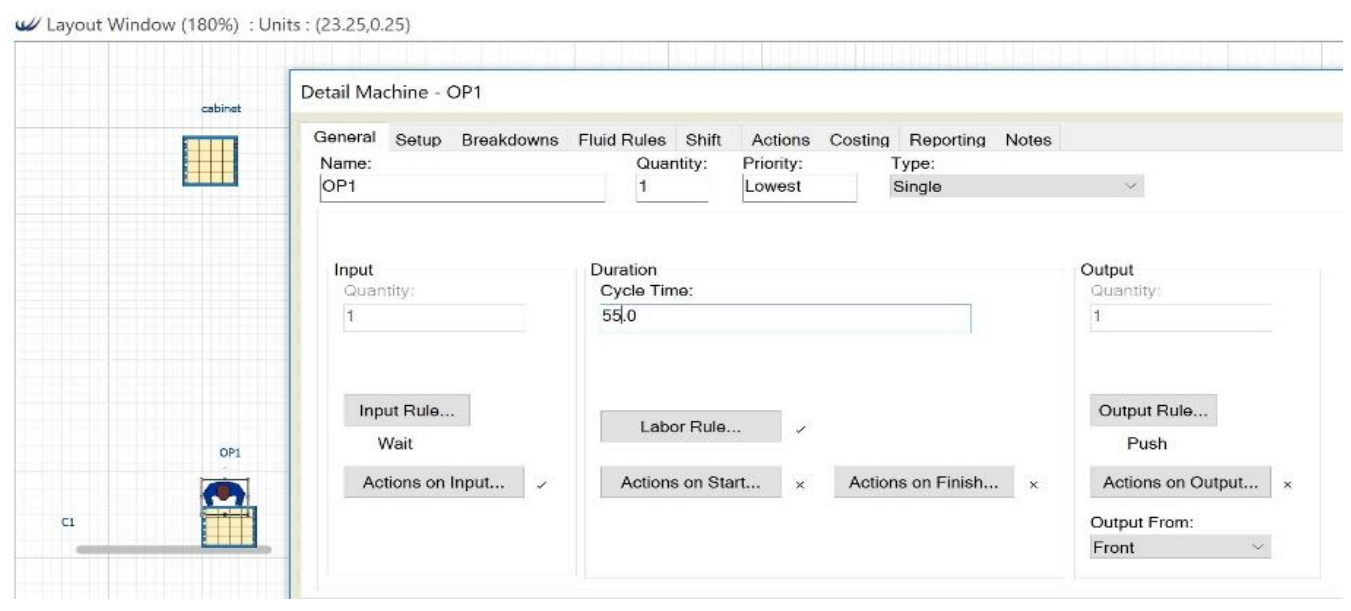

Fig. 2. Manufacturing times for the first operator 
Figure 2 represents a WITNESS Horizon capture corresponding to OP1 necessary manufacturing time according to its assembly operations.

cabinet

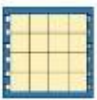

count

445
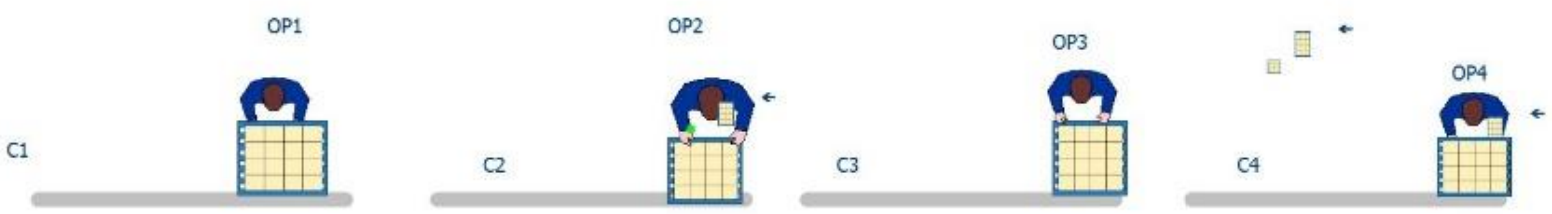

Fig. 3. Area 1 WITNESS Horizon corresponding model during the simulation

After finishing an 8 hours material flow simulation 512 cabinets were assembled in the first production sector. Several activity reports were created in order to help us diagnose this sector. The work time percentage is above $85 \%$. Operator OP3 has the longest waiting time.

In a similar way the model for the second studied area was build. The structural elements used were resembling to the first model used in different quantities: operators (named OP1 - OP3); transport systems (named C1 - C4); assembly (named cabinet).

The roles of the operators are as follows: OP1 - cleans cabinet, interior and puts the baskets inside the cabinet; OP2 checks the overall door characteristics, positions the door, and fixed the left hinge on the cabinet. The OP3 operator positions and fixes the right hinge on the cabinet, prepares and mounts the lamp cable; checks to see if the door is well fixed and the gasket sealed.

The manufacturing times in percent for the second area are given in Figure 4.

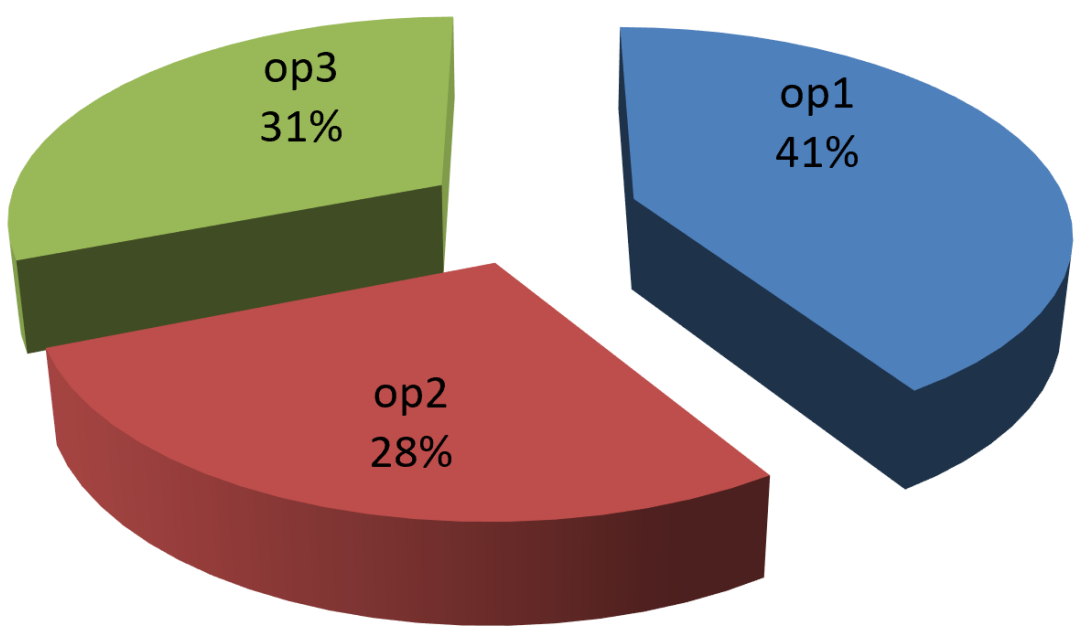

Fig. 4. Work times in percent for the second area 


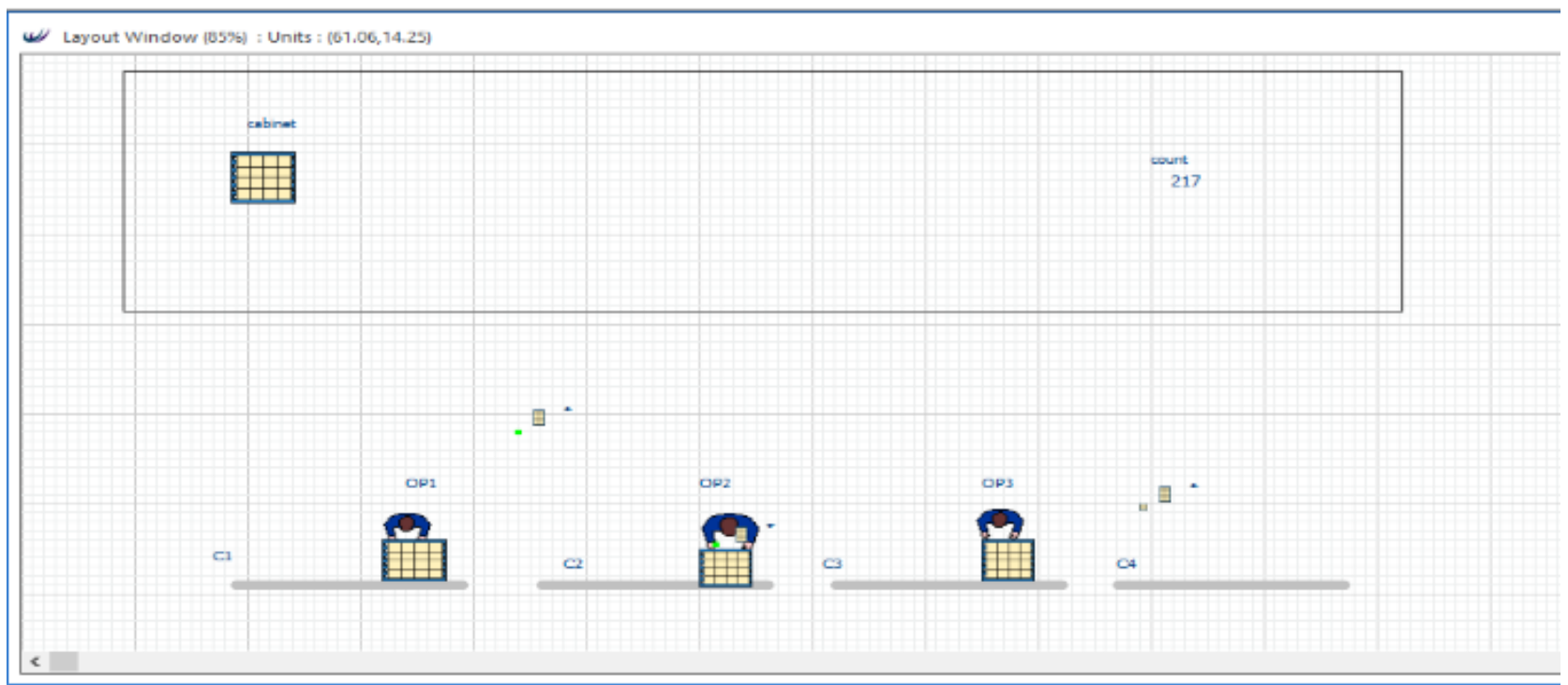

Fig. 5. Second assembly space WITNESS Horizon corresponding model during simulation

After simulating the material flow in the second assembly area one can notice that the cabinet number entered are processed before the work shift ended, in approximately 7 hours. The assembly capacity for this sector is 655 cabinets (Figure 5).

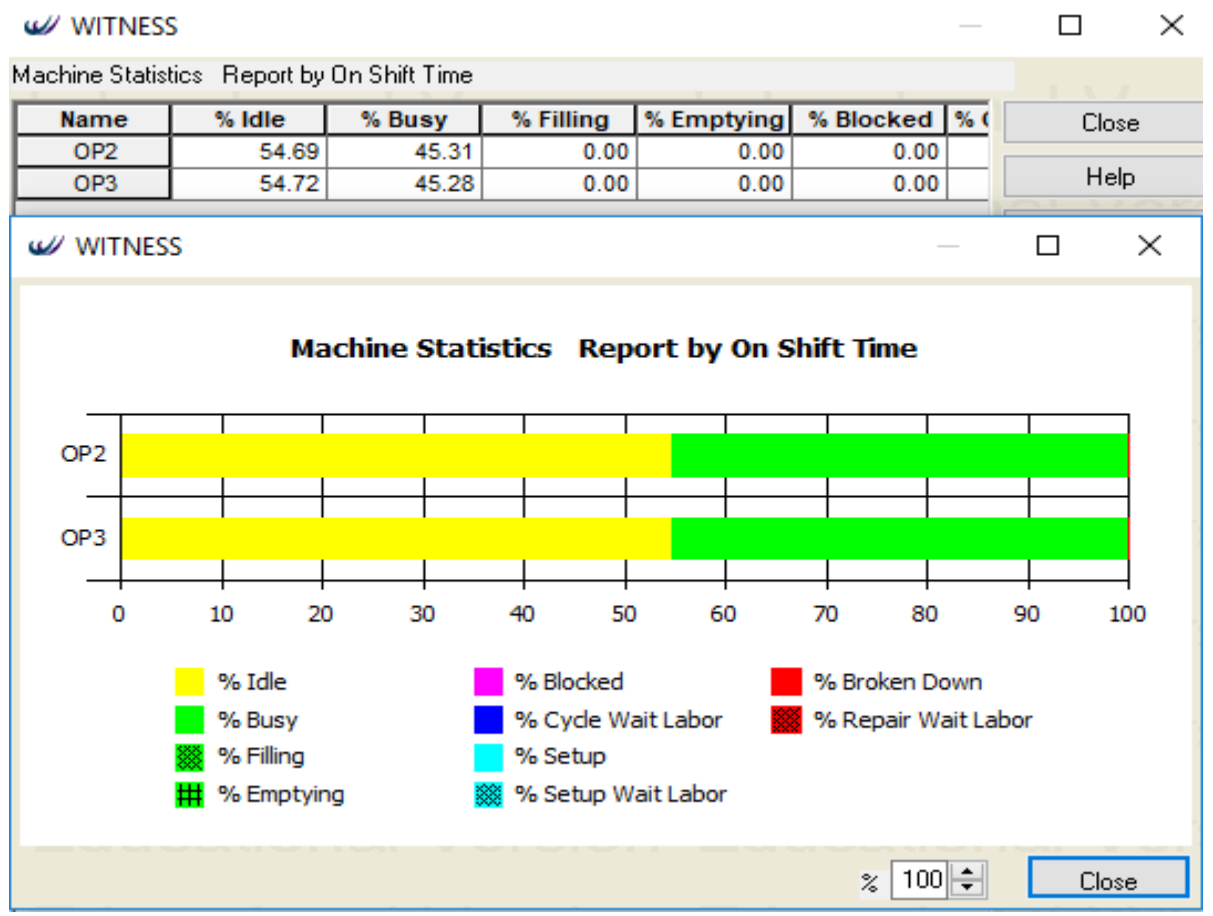

Fig. 6. Activity report for OP2, OP3

Because OP1 has a manufacturing time almost two times bigger than the other two operators we expect a flow concentrator in this area. This fact is confirmed by the activity report (Figure 6) that clearly states the percentage for the idle time.

In order to create the WITNESS Horizon model for the last studied sector we used: human operators; transport systems and the assembled part.

In this area the operators make the following operations: OP1 - fixes the condenser; OP2 - verifies the status of the compressor and positions and assembles it; OP3 - fixes the lamp and the power cord in brackets. He also puts the thermostat cable in the bracket; OP4 - positions the thermostat cable and the grounding conductor in the compressor socket; OP5 - introduces the condenser coil in the filter drier and in the discharge compressor pipe; OP6 - makes the piping brazing for aspiration and discharge. The manufacturing times distribution for the third area is presented in figure 7. 


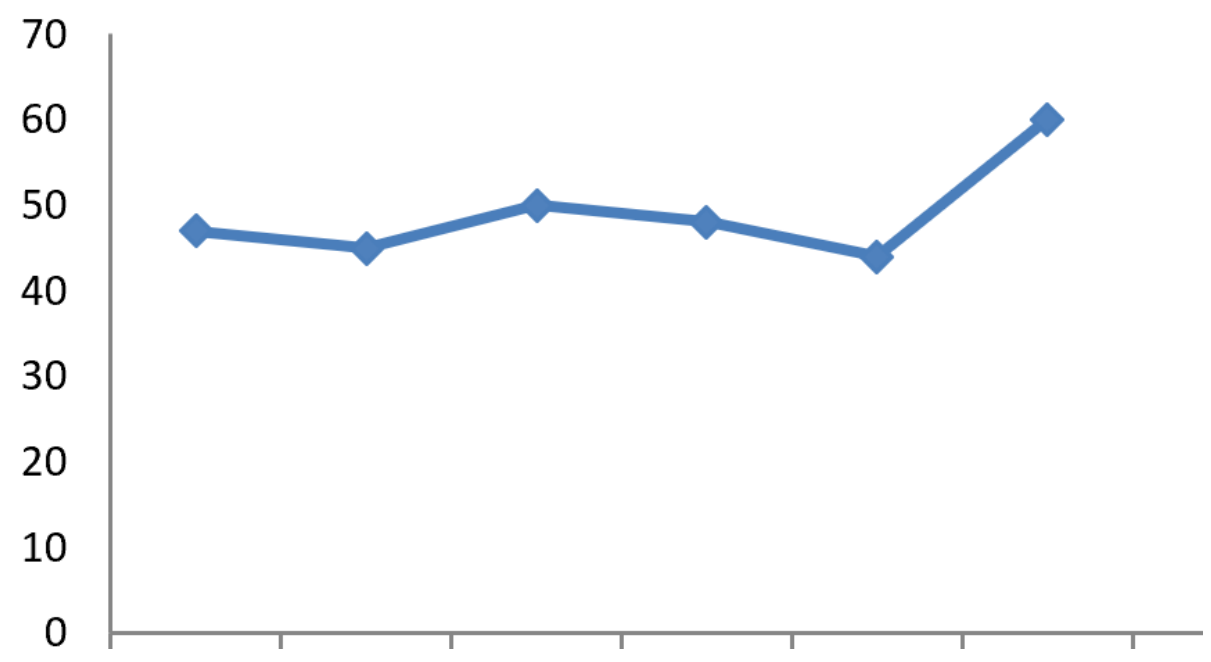

Fig. 7. Working times in aria 3

The total assembled parts during a work shift in this area is 423 (Figure 8). The necessary time to assemble all 512 parts is nine hours and 40 minutes.

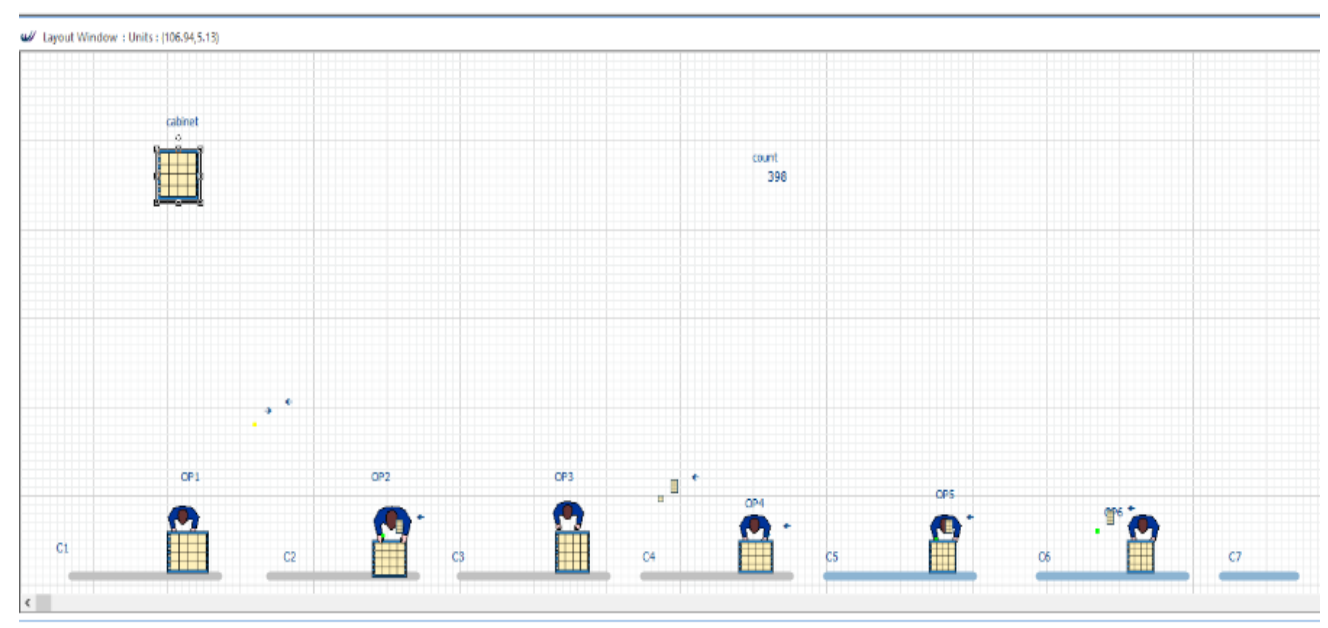

Fig. 8. Area 3 WITNESS Horizon corresponding model after simulation

In order to correctly diagnose the system activity reports were generated for all structural elements. A percentage comparison was made between manufacturing and idle times.

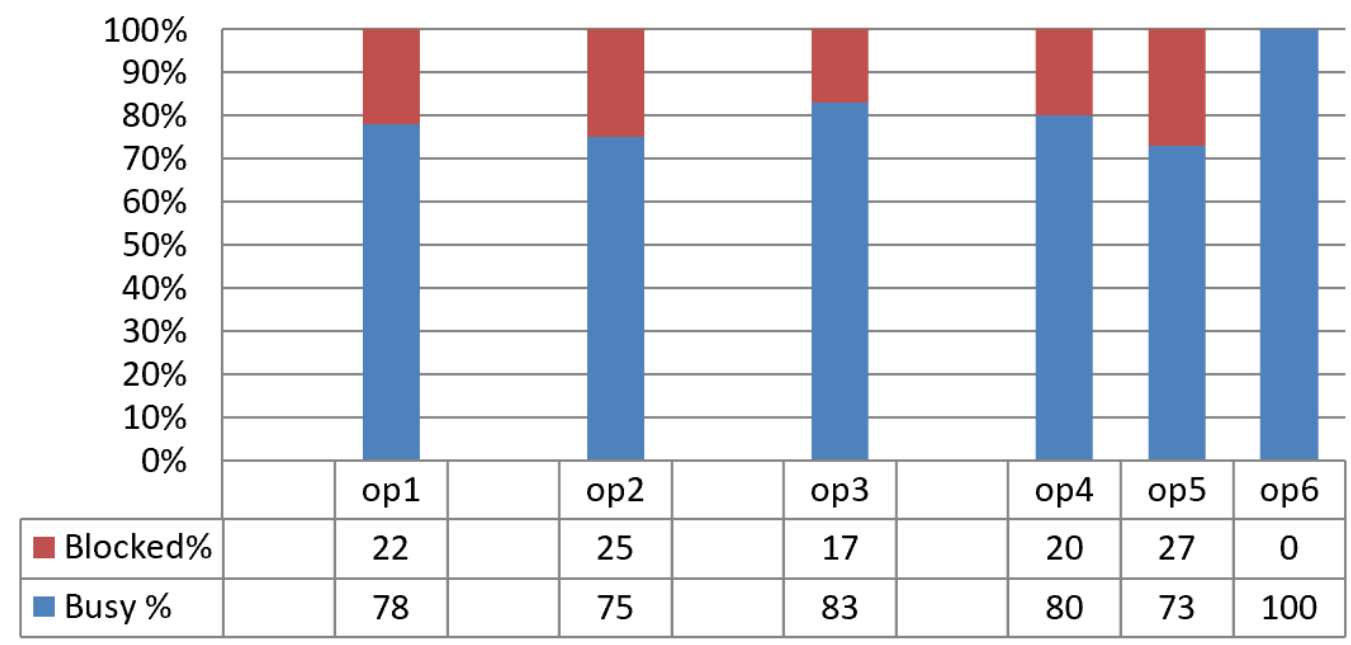

Fig. 9. Structural elements activity reports 


\section{Optimisation}

For improving the productivity, we propose to reorganise the displacement of this area by adding additional operators and balancing some of the existing operations.

For the first area we decided to add another human operator and a conveyor belt. In addition to that we also decreased the auxiliary time. Once we balanced the operations carried in the first working area, we obtained the following manufacturing times (Figure 10).

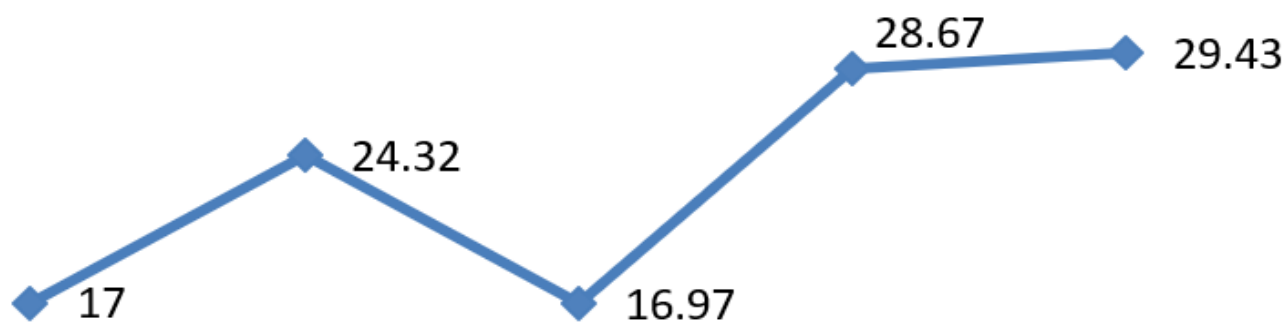

$\begin{array}{lllll}\text { op1 } & \text { op2 } & \text { op3 } & \text { op4 } & \text { op5 }\end{array}$

Fig. 10. First area manufacturing times after optimisation

The new manufacturing architecture material flow was simulated for the same period of time and the production rate was increase to 982 cabinets (figure 11).

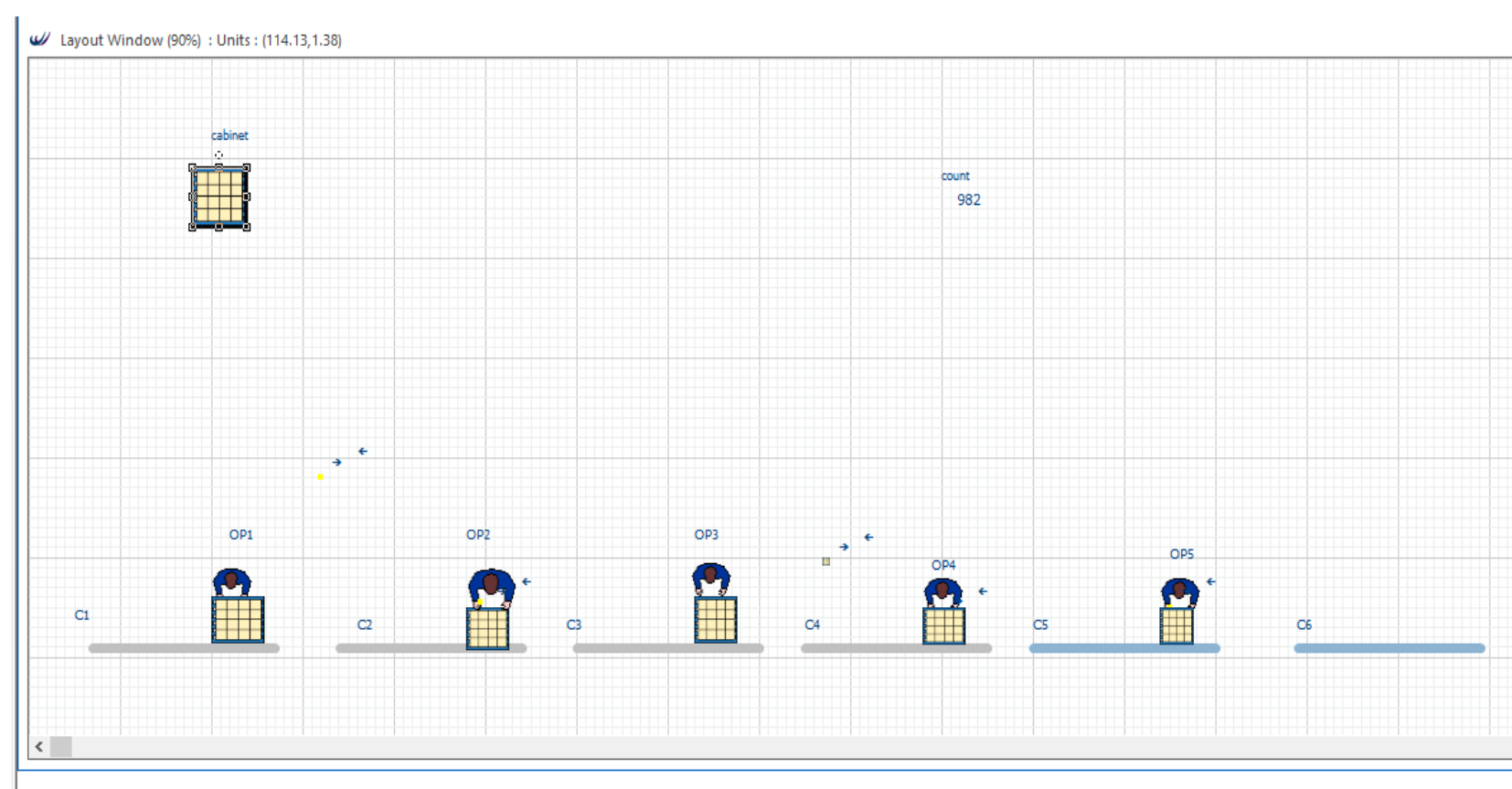

Fig. 11. First area optimisation and results

Analysing the results obtained after simulating the preliminary architecture material flow of the second area we noticed the under use of its work capacity. It was able to assembly 655 cabinets in a work shift, while the input was 512 . However, the new input is 982 cabinets and for that we optimised this area by introducing one more operator and his corresponding conveyor belt. In Figure 12 we presented the manufacturing times used in the new simulation. 


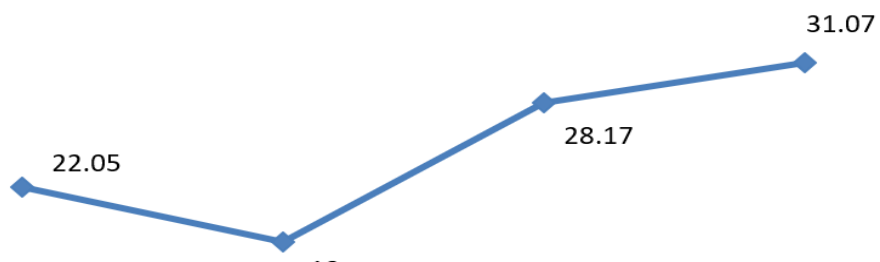

18

op1

op2

ор3

op4

Fig. 12. Second area manufacturing times after optimisation

After we rebuilt the manufacturing architecture, added the new manufacturing times and the conveyor speed a new simulation was performed (Figure 13).

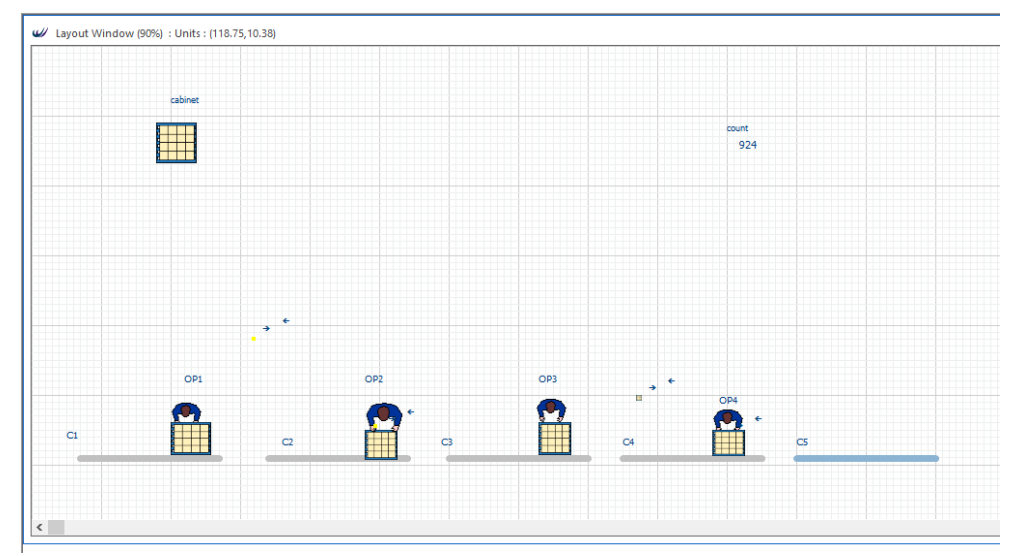

Fig. 13. Second area material flow simulation

In one work shift this area is capable to process 924 cabinets. We observed that the optimisation it is not enough because the productivity rate of the first area is bigger than that.

The simulation results for the last analysed area revealed a productivity of 423 cabinets that represents less than the number of cabinets manufactured in the first area. The proposed solution was to reorganise the operations and their manufacturing times (figure 14).

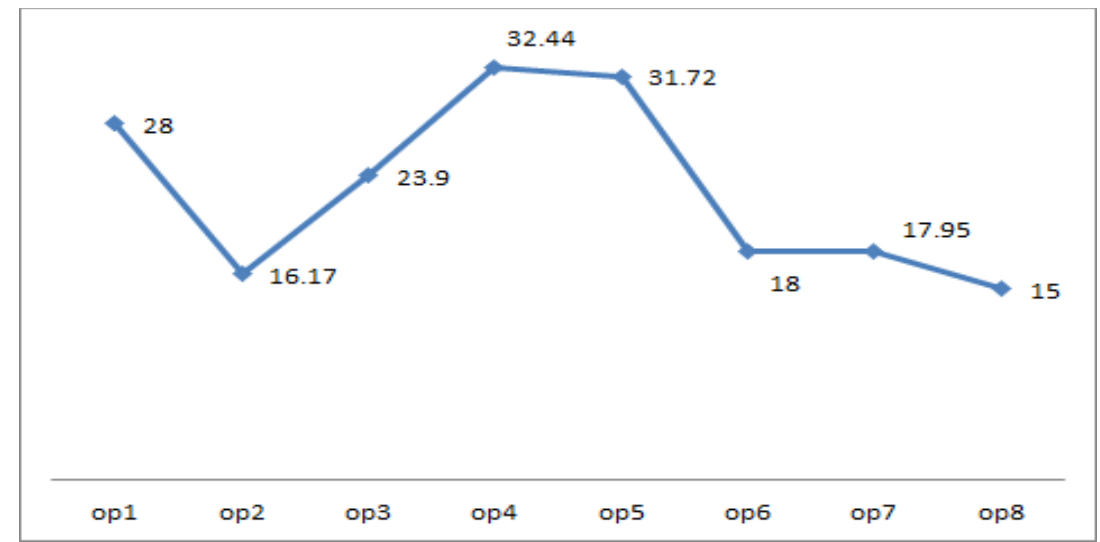

Fig. 14. Third area new manufacturing times

The optimised architecture consists in 8 human operators and 9 conveyor belts as shown in the model described in Figure 15. 


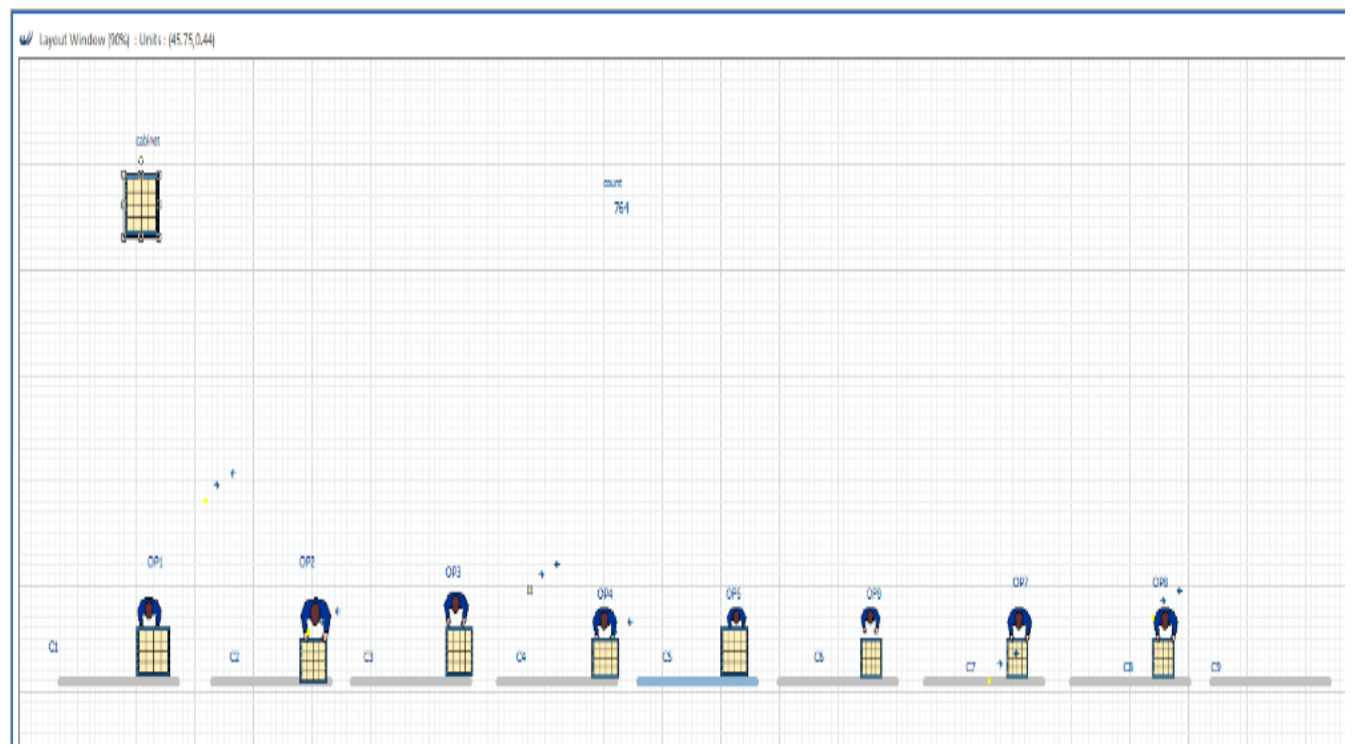

Fig. 15. Optimised manufacturing architecture of third area

This manufacturing architecture diagnose reveals a production of 764 cabinets per one work shift. The new input consists in 924 cabinets.

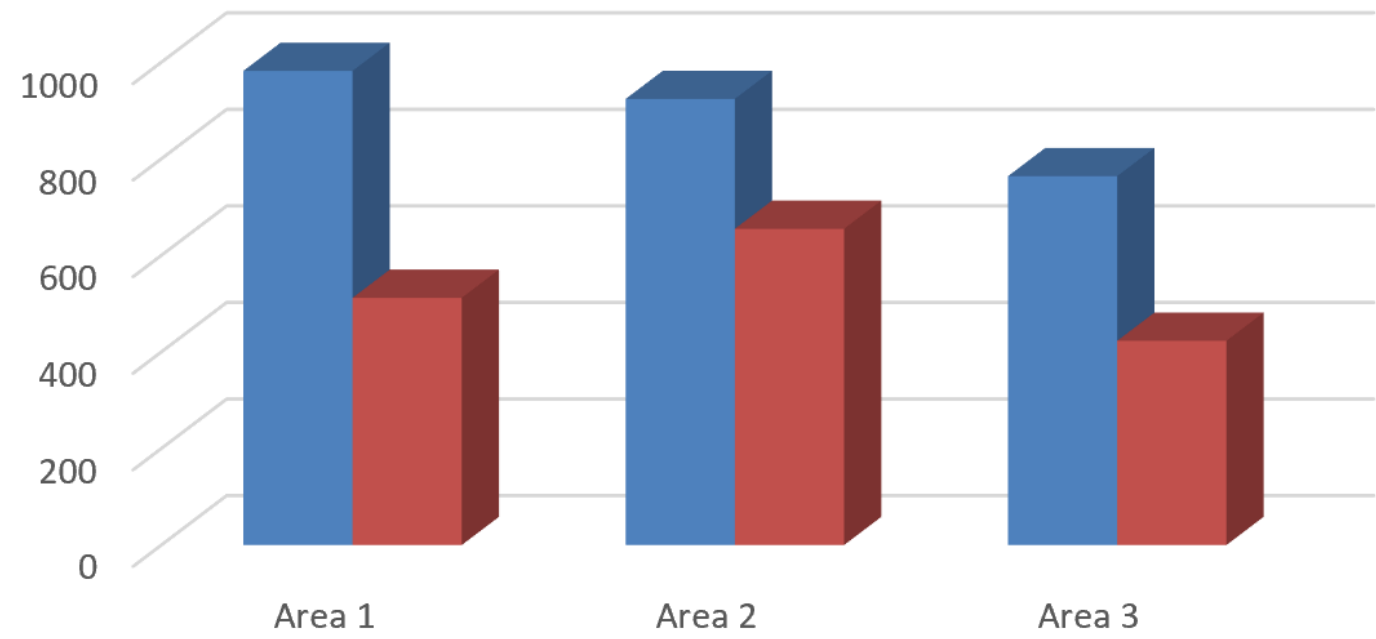

Fig. 16. Productivity rates for preliminary and optimised manufacturing architectures

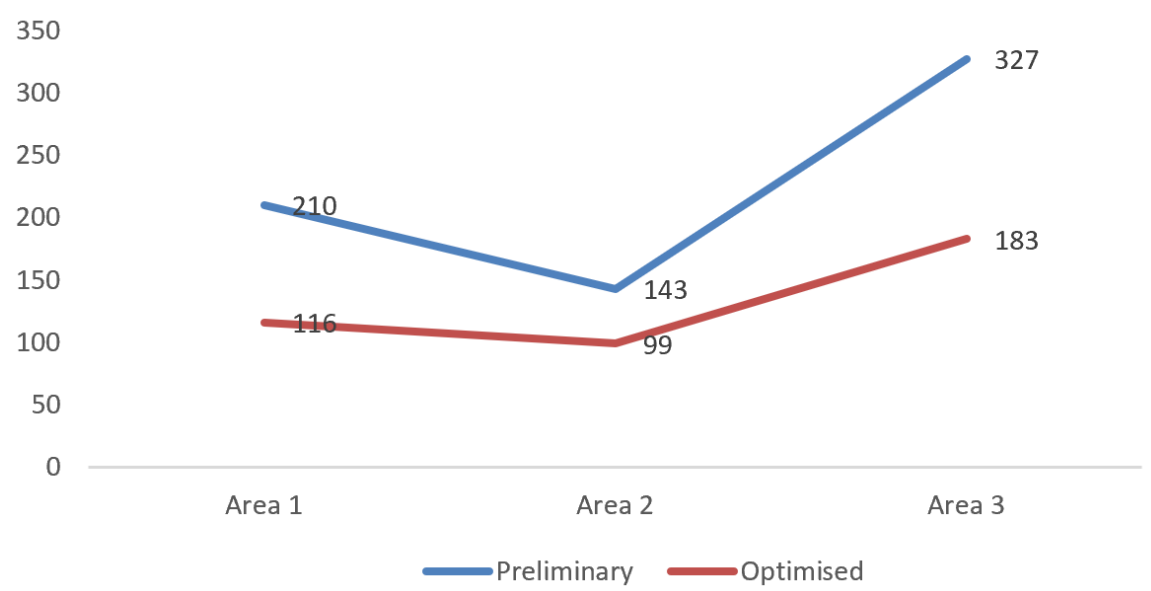

Fig. 17. Manufacturing times for preliminary vs. optimised architectures 


\section{Acknowledgments}

Funding: This work has been funded by University POLITEHNICA of Bucharest, through the "GNAC ARUT Program”, UPB - GNAC ARUT. Identifier: UPB-GNAC ARUT-2018 Research project title: IOT platform material flow management in industry 4.0, Contract number: 162/ 01.10.2018

Acknowledgments: This work has been funded by University POLITEHNICA of Bucharest, through the "GNAC ARUT Program". Identifier: UPB-GNAC ARUT Program-2018 Research project title: IOT platform material flow management in industry 4.0, Contract number: 162/ 01.10.2018

\section{Conclusion \& Further intensions}

The main goal of this research is to improve the diagnose of various manufacturing and processing architectures providing specific optimisation algorithms for discrete material flows. We illustrated this stage of our approach with a study case from chest freezing manufacturing. We used technological remodelling in order to optimise the system by decreasing auxiliary times.

Overall one can notice a productivity growth for all studied areas, as shown in Figure 16.

Generally, all manufacturing processes were reorganised, which lead to reduced manufacturing times in all studied areas (figure 17).

The optimisation process was both functional (we increased some conveyor belts speed) and technological (we added human operators and conveyors belts).

The optimised manufacturing architecture corresponding to the first area had more than doubled the productivity.

For area two although the number of assembled cabinets increased, it doesn't have the necessary capacity to process the input number of cabinets. Tests showed that be adding another workstation and reassigning the operations this area can even deal with an increase input.

The third area is the most difficult one to optimise due to the big number of operations carried on. New workstations were introduced, in the same way as for the first two areas and the productivity increased by $92 \%$ which represents the smallest growth from all three areas. Due to this fact we can consider this area to be a flow concentrator for the whole manufacturing architecture.

As a general conclusion we achieved our goal for increasing the overall productivity.

Based on the system diagnosis our further intension is to eliminate the new bottleneck in the third area, responsible in the same time for the whole manufacturing architecture productivity rate.

\section{References}

[1] IBIS World Refrigerator \& Freezer Manufacturing Industry in the US. Industry Market Research Report. Available at:https://www.ibisworld.com/industry-trends/specialized-market-research-reports/consumer-goodsservices/houseware-manufacturing/refrigerator-freezer-manufacturing.html (2018)

[2] U.S. Bureau of Labor Statistics, Producer Price Index by Industry: Household Refrigerator and Home Freezer Manufacturing: Parts and Attachments for Household Refrigerators and Freezers, Available at: https://fred.stlouisfed.org/series/PCU3352223352223 (2019)

[3] R.H. Mascheroni, V.O. Salvadori. (2016) Household Refrigerators and Freezers. Handbook of Frozen Food Processing and Packaging (Da-Wen Sun)

[4] S.F. Pearson, IIR Bulletin 3, 5-25 (2004)

[5] J.K. Gupta, M. Ram Gopal, S. Chakraborty, Int. J. of Refrig. (2007) 30, 311-322

[6] X. Guo, Y. Zhang, K. Xu. (2016) Metallurgical recovery of metals from Waste Electrical and Electronic Equipment (WEEE) in PRC ( John Wiley\&Sons)

[7] C.L. Popa, C.E. Cotet. (2017) Lect. Not. in Mech Eng., 41-55

[8] M. Ayadi, R.C. Affonso, V. Cheutet, F. Masmoudi, A. Riviere, M, Haddar. (2013) Int. J. of Sim.Mod. 12, 107-119,

[9] Enache Ioana Catalina, Chiscop Florina, Simion Ionel, Funar Stefan Petru. (2012). Manufacturing architecture diagnosis using discrete material flow management, Annals of DAAAM for 2012 \& Proceedings of the 23nd DAAAM Symposium "Intelligent manufacturing and Automation: Power of Knowledge and creativity", 24-27th October 2012, Zadar, Croatia, Volume 23, No.1, ISSN 2304-1382 ISBN 978-3-901509-91-9, CDROM version, Ed. B. Katalinic, Published by DAAAM International, Vienna, Austria, EU, 2012 